\title{
Theoretical Estimates of Consumable Food and Probability of Acquiring Food in Larvae of Chrysomya putoria (Diptera: Calliphoridae)
}

\author{
WAC Godoy, CJ Von Zuben* $/+$, SF dos Reis ${ }^{* *} /+{ }^{++}$, FJ Von Zuben ${ }^{* * *} /+$
}

\begin{abstract}
Departamento de Parasitologia, IB, Universidade Estadual Paulista, 18618-000 Botucatu, SP, Brasil *Curso de Pós-graduação em Ciências Biológicas, Universidade Estadual Paulista, 13506-900 Rio Claro, SP, Brasil

*** Departamento de Parasitologia, IB, Universidade Estadual de Campinas, Caixa Postal 6109, 13083-970 Campinas, SP, Brasil ${ }^{* * *}$ Departamento de Computação e Automação Industrial, FEE, Universidade Estadual de Campinas, 13083-970 Campinas, SP, Brasil
\end{abstract}

An indirect estimate of consumable food and probability of acquiring food in a blowfly species, Chrysomya putoria, is presented. This alternative procedure combines three distinct models to estimate consumable food in the context of the exploitative competition experienced by immature individuals in blowfly populations. The relevant parameters are derived from data for pupal weight and survival and estimates of density-independent larval mortality in twenty different larval densities. As part of this procedure, the probability of acquiring food per unit of time and the time taken to exhaust the food supply are also calculated. The procedure employed here may be valuable for estimations in insects whose immature stages develop inside the food substrate, where it is difficult to partial out confounding effects such as separation of faeces. This procedure also has the advantage of taking into account the population dynamics of immatures living under crowded conditions, which are particularly characteristic of blowflies and other insects as well.

Key words: Chrysomya putoria - density-independence - exploitative competition - consumable food population dynamics

Knowledge of the nutritional requirements of insects and their interaction with food sources are basic for an understanding of their biology, since the amount and quality of food affect the growth rate at the immature stage and subsequent adult body size (Scriber \& Slansky 1981, Farrar et al. 1989). In completely favorable environments the performance of each individual is genetically determined, which in turn determines its maximal fitness in nutritional terms (Slansky \& Rodriguez 1987). Nevertheless, environmental factors including density dependent mechanisms may be responsible for constraints on the consumption, utilization and allocation of food (Nicholson 1954, Rodriguez 1988, Travis 1990), with attendant consequences for the dynamic behaviour of populations (Mueller 1988).

In calliphorid flies, the major period of resource limitation occurs during the larval stage, and

\footnotetext{
This work was supported by grants from FAPESP (No 94/3851-9 and 94/5355-9).

${ }^{+}$Research Fellow CNPq

${ }^{++}$Corresponding author. E-mail: sergio@ @uring. unicamp.br

Received 11 September 1995

Accepted 3 January 1996
}

their mode of competition for food is generally considered as the exploitative type, where the larvae scramble for food, each one trying independently to acquire as much food as possible before it is completely exhausted (Levot et al. 1979, Lomnicki 1988). Some larvae end up with more food than the minimal required for survival, others reach just the minimal amount, whereas some are not able to reach this minimal necessary for pupariation and die (de Jong 1976). The food eaten by the dead individuals is therefore wasted, and this situation is inherent to scramble competition when resource is in short supply (de Jong 1976, Levot et al. 1979, Lomnicki 1988).

The relative rate of consumption is a parameter commonly employed for quantifying the behavioural response of insects with respect to the food source (Waldbauer 1968), although in certain cases the outcome of larval competition for food is perhaps more closely approximated to larval assimilation than to true consumption (Putman 1977). Essential for studies of nutritional ecology are research techniques that employ biochemistry, physiology, genetics and behaviour of organisms (Slansky \& Rodriguez 1987). Gravimetry has been used in several studies of food assimilation for distinct orders of insects (Waldbauer 1968, Holter 1982, Zheng et al. 1993). Other procedures may also be used such as some types of marker meth- 
ods (Mcginnis \& Kasting 1964, Holter 1973, Hanski 1976, Barbehenn 1993), chromic oxide (Holter 1973), radioactively labelled yeast (Miranda \& Eggleston 1988), silicon markers (Barbehenn 1993) and the number of cephalopharingeous retractions during the larval feeding process (Mueller 1988).

The estimation of consumable food by all survivors through the above techniques is nevertheless very difficult to obtain in insects whose immature stages develop inside the food substrate, like blowflies, because larval faeces would make up part of food left over. This situation can impede the separation of faeces from the remaining substrate (Schumann 1971, Hanski 1976). Estimates of consumable food in insects whose larval stages are usually exposed to severe exploitative intraspecific competition must, by necessity, be made in a context of population dynamics.

Herein, we present an alternative method for theoretical estimation of consumable food by survivors until pupariation, in different larval densities of Chrysomya putoria, a blowfly recently introduced in Brazil (Guimarães et al. 1978) and associated with decomposing organic matter, mainly in urban areas (Linhares 1981, Guimarães 1984, d'Almeida \& Lopes 1983, d'Almeida 1989, 1993). This species has considerable medical and sanitary importance, because it can be a mechanical vector of pathogens (Greenberg 1971), and also produce secondary myiasis in man and other animals (Zumpt 1965).

Our procedure combines three different models which address the problem of consumable food by the survivors in a context of population dynamics. This approach combines estimates of densityindependent larval mortality (Morris 1990) to infer the amount of food consumable according to Ullyett (1950), using pupal weight and survival data. The key calculations are based on a theoretical mean value of efficiency of conversion of ingested food (ECI) obtained in saprophagous invertebrates by Heal (1974) (see review in Slansky \& Scriber 1982). The probability of acquiring food per unit of time, the time in discrete units necessary for the larvae to attain the minimal pupal weight, and the time taken to exhaust the food supply were also calculated (de Jong 1976), because of their importance for organisms that compete for limited amounts of food such as the majority of larvae of calliphorid flies.

\section{MATERIALS AND METHODS}

Laboratory populations of Chrysomya putoria - Laboratory populations of C. putoria were founded from specimens collected from the campus of "Universidade Estadual de Campinas",
Campinas, São Paulo, Brazil, using carrion rodent baits. Adult flies were maintained in cages $(30 \mathrm{x}$ $30 \times 48 \mathrm{~cm}$ ) covered with a nylon mesh at $25 \pm 1^{\circ} \mathrm{C}$, $60 \%$ relative humidity and $12 \mathrm{hr}$ photophase, being fed water and sugar ad libitum. Adult females were fed fresh beef liver to allow their complete gonotrophic cycle. Second laboratory generation $\left(F_{2}\right)$ was used in experiments.

Estimation of consumable food by the survivors - The theoretical amount of consumable food was estimated by the model proposed by Ullyett (1950), asserting that a certain amount of food theoretically allows the development of a given number of individuals of maximum weight. However, Ullyett makes an assumption of a theoretically value of $100 \%$ of food conversion into biomass, which is very unrealistic. In the present study, we utilize an ECI of 39\%, considered by Heal (1974) as a mean value for saprophagous invertebrates. For insects, such as blowflies, whose larvae experience competition for food, the maximum weight will, to a large extent, depend on the degree of larval crowding, which is known to impose constraints both in the number and weight of survivors. In this study maximum weight was measured at the pupal stage for a range of larval densities which reproduces the process of exploitative competition characteristic of blowflies (Godoy et al. 1993). Accordingly to adopted ECI, for a larva to attain a given weight as a pupa, it must feed an amount equivalent to 2.5641 times its pupal weight.

Twenty different larval densities ranging from 100 to 2,000 larvae with intervals of 100 were established using $50,000 \mathrm{mg}$ of rearing medium per vial $(7.2 \mathrm{~cm}$ diameter $x 13.8 \mathrm{~cm}$ height), prepared according to Leal et al. (1982). These larval densities are equivalent from 2 to 40 individuals per $g$. The rearing medium was chosen in order to control the amount of protein content and to avoid extraneous variation that might be introduced with other media such as liver or carcass. Survival was estimated as the number of adults emerging per vial, and the mean number of adults was calculated from four replicate vials for densities of 100 to 500 larvae, three vials for densities of 600 to 900 , two vials for densities of 1,000 to 1,300 and finally one vial for the remaining densities. Pupae totals were counted in each vial, and weights were estimated by weighing thirty pupae (nine days old) for each replicate in all densities, except for densities 1,400 and 1,500 where 23 pupae were weighed. The mean for number of pupae and pupal weight, and the values for minimal and maximum pupal weight were computed for each density.

The expected number of pupae of maximum weight that could be produced by the amount of food available is obtained by dividing the latter by 
the maximal mean of pupal weight (multiplied by 2.5641) obtained for each density. Consequently, the unconsumable portion of food corresponded to the difference between the number of pupae expected if all food were consumed by the survivors and the number of pupae actually obtained experimentally for each density (Ullyett 1950).

The model by Ullyett (1950) requires an estimate of larval density-independent mortality, which is estimated here using the approach advanced by Morris (1990), following an earlier formulation due to Hassell et al. (1976). Hassell et al. (1976) proposed a method that can be used to estimate model parameters from population data, whose equation is written as

$$
\ln \left(N_{t} / N_{s}\right)=\beta \ln \left(1+\alpha N_{t}\right)
$$

where $N_{s}=N_{t+l} / \lambda$ is interpreted as the number of individuals surviving the density dependent stage in the life cycle whereas the number entering the stage is $N_{t}$. The maximum per-capita replacement rate per generation is written as $\lambda$ and the parameters $\alpha$ and $\beta$ determine how steeply the realized per-capita replacement rate declines in response to increasing larval density. The term on the left size of the equation define the " $k$ value" (Varley \& Gradwell 1960) associated with mortality during the density-dependent stage.

Morris (1990) modified this approach slightly, allowing density-independent mortality in the density-dependent stage by performing a non-linear regression of $k$-value mortality against density using the following modified version of the equation (1)

$$
k=\ln \left(N_{t} / N_{s}\right)=\beta \ln \left(1+\alpha N_{t}\right) \ln \gamma,
$$

where $\gamma$ represents density-independent mortality, subject to the constraint that $\gamma \leq 1$. Table II shows the mean percentage of individuals surviving in the replicates utilized to fit the parameters necessary for the computation of $\gamma$. Error estimates were obtained for each parameter. All estimates were performed by non-linear regressions using NLIN module of the SAS-PC (SAS Institute 1988), which uses a Newton algorithm to search for best-fit parameters.

Estimation of probability of acquiring food per unit of time and time taken to exhaust food (de Jong 1976) - (1) One type of food is present for which $n$ larvae compete. A finite amount of particles of food $(M)$ in $\mathrm{mg}$ is present; (2) A minimal quantity in $\mathrm{mg}$ $(m)$ has to be eaten for a larvae to become adult; (3) Time can be counted in discrete units and is measured arbitrarily; in 1 time unit a larva eats either one or no food particles; (4) A larva eats at least the equivalent to the weight it will attain as a pupa (multiplied by 2.5641), to complete its de- velopment; (5) The time of exhaustion of food in discrete units is $t$ and $T$ is the maximum time of the larval stage; (6) The probability per time unit $(P)$ that a larva is feeding represents the average probability of acquiring food per time unit during the complete larval stage.

The time $t$ taken to exhaust food equals the total number of food particles divided by the number eaten per time unit, and rounded to the nearest integer (int):

$$
t=\operatorname{int}\left(\frac{M}{P . n}+0.5\right)
$$

It follows from assumptions 3 and 4 that the maximum amount of food a larva can possibly acquire is equal either to $t$, in the case of exhaustion of food, or to $T$, in the case of plentiful food supply. The probability of a larva eating $x$ food particles is, according to the binomial distribution:

$$
P(x)=\left(\begin{array}{l}
t \\
x
\end{array}\right) P^{x}(1-P)^{t-x}, x \leq t \leq T .
$$

For survival of a larva into adulthood it is necessary that $x \geq m$. The probability of survival or viability $v$ is equal to the probability of acquiring any number of food particles $i$ with $m \leq i, i \leq t \leq T$,

$$
v=\sum_{i=m}^{i=t}\left(\begin{array}{l}
t \\
i
\end{array}\right) P^{i}(1-P)^{t-i}, t \leq T .
$$

The mean amount of food eaten by each survivor, $E$, is:

$$
E\{i \mid i \geq m\}=\frac{1}{v} \sum_{i=m}^{i=t} i\left(\begin{array}{l}
t \\
i
\end{array}\right) P^{i}(1-P)^{t-i}, t \leq T .
$$

The total amount of consumable food by the survivors, $B$, is given using equations (5) and (6):

$$
B=\text { n.v.E }
$$

The best fitting values for the above parameters were obtained through simulations using MATLAB (1987).

\section{RESULTS}

Theoretical estimates of consumable food by the survivors, used in this study in C. putoria, require data on pupal weight and survival rates (Ullyett 1950). The minimal, maximum, and mean pupal weights, the minimal/maximum pupal weight ratio, and the survival rates of $C$. putoria in densities ranging from 100 to 2,000 larvae are given in Table I, and the mean number of pupae in each of the densities is demonstrated in Table II. In the context of the present study the maximum mean weight of the pupae is of particular interest because (1) it varies with larval density and (2) this value is necessary for the computation of the maximum amount of consumable food by the survivors for 


\section{TABLE I}

Mean and standard deviation (SD), minimal and maximum values, and minimal/maximum ratios for pupal weight (mg) for Chrysomya putoria in 20 larval densities

\begin{tabular}{|c|c|c|c|c|c|}
\hline \multirow[b]{2}{*}{ Density } & \multicolumn{2}{|c|}{ Pupal weight } & \multicolumn{2}{|c|}{ Weight } & \multirow{2}{*}{$\begin{array}{c}\text { Minimal maximum } \\
\text { ratio }\end{array}$} \\
\hline & $\mathrm{N}$ & Mean \pm SD & minimal & maximum & \\
\hline 100 & 120 & $32.49 \pm 10.68$ & 3.9 & 55.3 & 0.07 \\
\hline 200 & 120 & $35.85 \pm 4.36$ & 19.9 & 45.5 & 0.44 \\
\hline 300 & 120 & $39.85 \pm 6.33$ & 18.8 & 52.3 & 0.36 \\
\hline 400 & 120 & $36.59 \pm 4.89$ & 19.6 & 47.4 & 0.41 \\
\hline 500 & 120 & $36.26 \pm 4.85$ & 20.5 & 47.5 & 0.43 \\
\hline 600 & 90 & $32.82 \pm 4.54$ & 22.6 & 41.6 & 0.54 \\
\hline 700 & 90 & $26.04 \pm 4.55$ & 13 & 38 & 0.34 \\
\hline 800 & 90 & $20.26 \pm 3.41$ & 11.2 & 30 & 0.37 \\
\hline 900 & 90 & $25.06 \pm 5.04$ & 11.8 & 38.2 & 0.31 \\
\hline 1000 & 60 & $24.50 \pm 6.18$ & 12 & 37.6 & 0.32 \\
\hline 1100 & 60 & $19.63 \pm 5.44$ & 9.6 & 30.9 & 0.31 \\
\hline 1200 & 60 & $13.87 \pm 4.03$ & 4.1 & 24.4 & 0.17 \\
\hline 1300 & 60 & $20.04 \pm 5.45$ & 10.5 & 31.5 & 0.33 \\
\hline 1400 & 23 & $12.86 \pm 2.56$ & 9.9 & 21.7 & 0.46 \\
\hline 1500 & 23 & $13.76 \pm 3.55$ & 6.8 & 22.5 & 0.30 \\
\hline 1600 & 30 & $22.56 \pm 3.85$ & 10 & 29.7 & 0.34 \\
\hline 1700 & 30 & $14.35 \pm 2.69$ & 7.9 & 20 & 0.39 \\
\hline 1800 & 30 & $19.70 \pm 3.82$ & 13 & 27.2 & 0.48 \\
\hline 1900 & 30 & $10.68 \pm 1.86$ & 7.9 & 14.7 & 0.54 \\
\hline 2000 & 30 & $10.75 \pm 2.90$ & 2.2 & 17.3 & 0.13 \\
\hline
\end{tabular}

TABLE II

Mean and standard deviation (SD) for percentage survival and total number of pupae of Chrysomya putoria in 20 larval densities

\begin{tabular}{|c|c|c|c|c|}
\hline \multirow[b]{2}{*}{ Density } & \multicolumn{2}{|c|}{ Percent survival } & \multicolumn{2}{|c|}{ Number of pupae } \\
\hline & $\mathrm{N}$ & Mean $\pm \mathrm{SD}$ & $\mathrm{N}$ & Mean \pm SD \\
\hline 100 & 4 & $73.25 \pm 3.86$ & 4 & $90.50 \pm 7.50$ \\
\hline 200 & 4 & $70.12 \pm 5.08$ & 4 & $146.25 \pm 7.89$ \\
\hline 300 & 4 & $39.66 \pm 5.47$ & 4 & $130.00 \pm 15.64$ \\
\hline 400 & 4 & $40.12 \pm 5.21$ & 4 & $170.00 \pm 27.47$ \\
\hline 500 & 4 & $44.70 \pm 5.29$ & 4 & $239.75 \pm 18.67$ \\
\hline 600 & 3 & $45.05 \pm 8.44$ & 3 & $282.66 \pm 54.42$ \\
\hline 700 & 3 & $52.95 \pm 2.06$ & 3 & $378.00 \pm 12.16$ \\
\hline 800 & 3 & $52.41 \pm 1.82$ & 3 & $432.66 \pm 15.04$ \\
\hline 900 & 3 & $38.92 \pm 3.52$ & 3 & $368.00 \pm 32.07$ \\
\hline 1000 & 2 & $25.10 \pm 4.24$ & 2 & $261.50 \pm 41.72$ \\
\hline 1100 & 2 & $20.95 \pm 3.66$ & 2 & $248.00 \pm 31.11$ \\
\hline 1200 & 2 & $19.41 \pm 2.24$ & 2 & $284.50 \pm 28.99$ \\
\hline 1300 & 2 & $25.38 \pm 1.08$ & 2 & $356.00 \pm 18.38$ \\
\hline 1400 & 1 & 9.35 & 1 & 149.00 \\
\hline 1500 & 1 & 10.93 & 1 & 195.00 \\
\hline 1600 & 1 & 7.18 & 1 & 126.00 \\
\hline 1700 & 1 & 13.64 & 1 & 298.00 \\
\hline 1800 & 1 & 18.00 & 1 & 349.00 \\
\hline 1900 & 1 & 7.94 & 1 & 153.00 \\
\hline 2000 & 1 & 4.65 & 1 & 105.00 \\
\hline
\end{tabular}


each larval density. For each larval density, the food available $(50,000 \mathrm{mg})$ divided by mean maximum pupal weight (multiplied by 2.5641 ) yields a theoretical number of larvae of maximum weight that could be produced under optimal conditions.

Survival rates allow to partial out density-dependent and density-independent mortality factors according to Morris (1990), which are also necessary for the theoretical estimation of consumable food. During the larval stage, there was a densityindependent mortality $\gamma=0.00612 \pm 0.00092$ corresponding to $0.6 \%$ mortality, considering all densities studied. It follows that the actual number of larvae of maximum weight that can be theoretically expected to develop in $50,000 \mathrm{mg}$ of food is $0.6 \%$ less in all larval densities. For each density, multiplying the observed values of mean pupal weight (Table I) and number of pupae formed (Table II), and dividing by the maximum pupal weight (multiplied by 2.5641), it is possible to calculate the equivalent number of pupae if they were of maximum weight.

Hence, the unconsumable portion of food for each density is reflected in the difference between the maximum number of pupae expected if all food was consumed by the survivors, and that actually obtained. The theoretical amount of consumable food by the survivors in twenty larval densities of C. putoria can be obtained through the multiplication of the initial amount of food utilized per vial in the experiment $(50,000 \mathrm{mg})$ by the percentage of pupae formed in relation to the maximum expected (Fig. 1). This figure shows that the higher values of amounts of consumable food corresponded to the densities of 500 to $900,1,300$ and 1,800 larvae.

Finally, the probability of acquiring food and the associated theoretical parameters were calculated for C. putoria, following de Jong (1976), using 50,000 $\mathrm{mg}$ of food for the development of the larval densities $(n)$, and considering the values of consumable food previously obtained for each den-

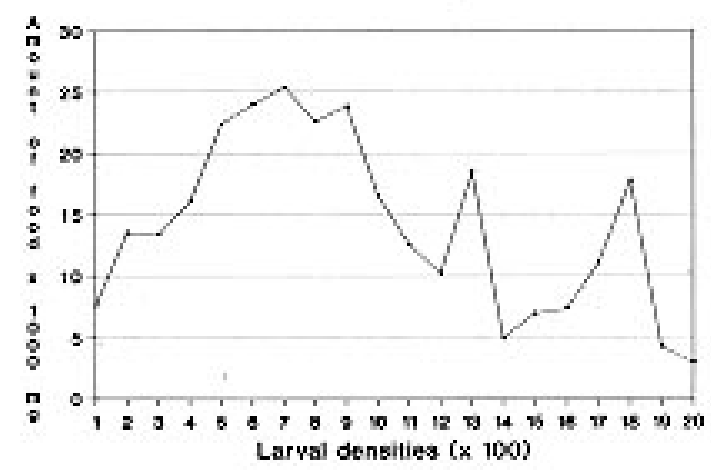

Fig. 1: theoretical amount of consumable food by larvae of Chrysomya putoria in 20 larval densities. sity (Fig. 1), as the parameter $B$ in de Jong's model. The best fitted values of the probability of acquiring food per unit of time, the time in discrete units necessary for the larvae to attain the minimal pupal weight, and the time $t$ taken to exhaust the food supply for the twenty larval densities of $C$. putoria are demonstrated in Figs 2, 3 and 4, respectively. The calculation of the time needed for the larvae to attain minimal pupal weight utilized the values of minimal pupal weight (Table I), whereas the calculation of time to exhaust food utilized the values of maximum pupal weight for each density (Table I). In comparison with the neighboring densities, higher values of probability of acquiring food are observed in the interval of 200 to 600 larvae, and also in the densities of 1,400 and 1,800 to 1,900 larvae (Fig. 2). The time taken for the larvae to attain the minimal pupal weight is larger in the densities of 200 to $600,1,100,1,300$ to $1,400,1,600$ and 1,800 larvae, when compared with their respective neighboring densities (Fig. 3), whereas the time taken to exhaust the food supply increases with increasing larval densities (Fig. 4).

\section{DISCUSSION}

The data utilized here for the theoretical estimates of consumable food in C. putoria were obtained for a range of larval densities, which entails

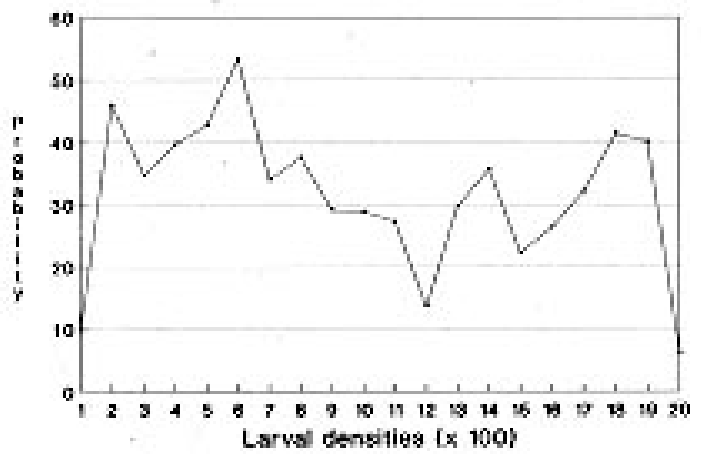

Fig. 2: probability of acquiring food per unit of time in Chrysomya putoria in 20 larval densities.

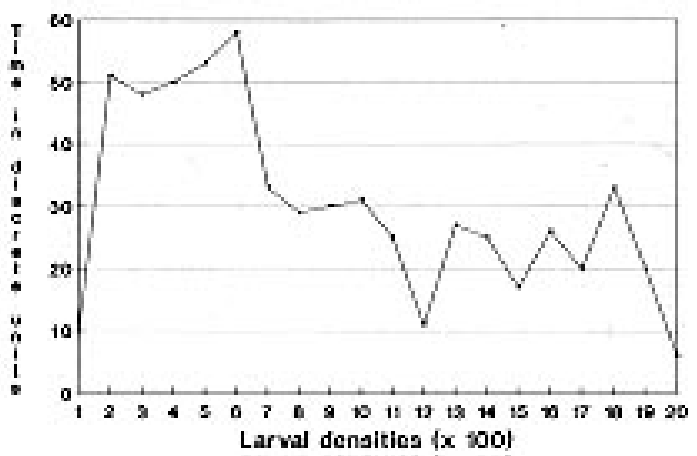

Fig. 3: time in discrete units necessary for larvae of Chrysomya putoria to achieve minimal pupal weight in 20 larval densities. 


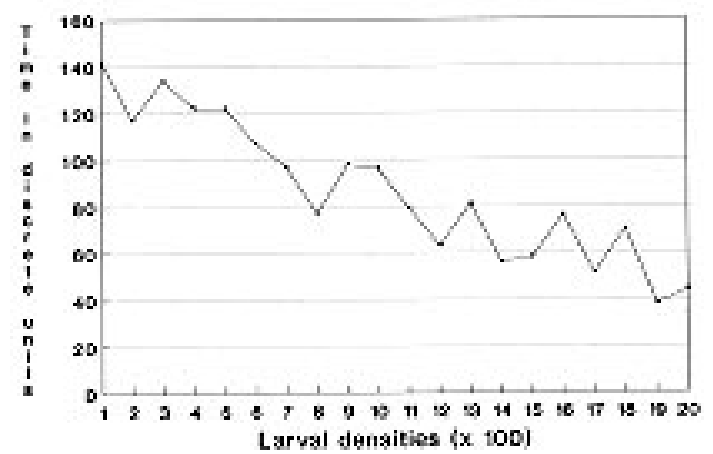

Fig. 4: time in discrete units taken for larvae of Chrysomya putoria to exhaust food supply in 20 larval densities.

high levels of competition for food and reproduces the characteristics of exploitative competition encountered in natural populations (de Jong 1976). The number of survivors until pupariation and the values of mean maximum pupal weight obtained for all densities in the experimental setting of the present study, are necessary for the estimation of the amount of consumable food by survivors, obtained through the model developed by Ullyett (1950).

This model considers the effect of density-independent larval mortality to obtain the theoretical value of consumable food, since the densityindependent mortality during the density-dependent stage yields a different estimate of composite parameters (Morris 1990), as that obtained by the method of Hassell et al. (1976). The small theoretical value of $0.6 \%$ obtained for this parameter in C. putoria could be explained by the high levels of competition experienced in the majority of densities performed here, characterizing a pronounced density-dependent effect on survival. This is probably related to the fact that the process of exploitative competition for food reproduced experimentally in this study showed high levels of mortality in the initial larval stage.

The high values of amount of consumable food by the survivors, obtained in the densities 500 to $900,1,300$ and 1,800 larvae are probably due to the high values of probability of acquiring food and number of pupae in these densities. The values in discrete units of time taken for the larvae to attain the minimal pupal weight, are usually larger in the densities where the minimal pupal weight is high, and the proportional difference between minimal and maximum pupal weights is small (which corresponds to higher minimal/maximum pupal weight ratios). Although in these densities the values of probability of acquiring food are usually high, more time in discrete units is necessary for the larvae to attain higher values of minimal pupal weight. The decrease in the values of discrete units of time needed for the larvae to exhaust the food supply, with increasing larval densities, is indicative of increasing levels of larval crowding and consequently scramble competition for food. It is worth noting that the amount of consumable food, the time needed for the larvae to attain minimal pupal weight, and the time to exhaust food are not monotonic functions of increasing larval densities. This occurs because the calculations of these parameters are based on values of consumable food whose variation also is not monotonic, probably due to variation in the number of pupae and pupal weight in increasing larval densities. The outcome of competition for limited resources in C. putoria depends on levels of mortality in the immature stages (Reis et al. 1994), which may be responsible for oscillations mainly in the number and size of pupae formed.

High values of probability of acquiring food per unit of time and consequently small times to exhaust the food supply, as obtained in some larval densities for $C$. putoria, are both indicative of rapid exhaustion of food resources. They also imply situations with high levels of larval competition for food, where all individuals try to acquire as much food as possible in a minimal possible interval of time, as expected from exploitative competition for food (de Jong 1976, Levot et al. 1979, Lomnicki 1988). In this case, the first larvae to attain the minimal weight required for growth and development during larval competition have the highest viability in their developmental trajectory (Denno \& Cothran 1976, Hanski 1987).

For larvae whose development occurs in ephemeral substrates, intraspecific competition can have an adverse effect on fitness traits such as survival and size, which has consequences for the population dynamics of the resultant adults (Norris 1965, Kneidel 1984, Goodbrod \& Goff 1990). In these substrates, conditions are suitable for rapid development and differences of only a few hours in the hatching time of the larvae may result in marked differences in the size of the larvae at later stages. This may be of major importance, especially in the case of small pieces of carrion, which probably predominate in nature, where resources may be consumed before the smaller larvae reach the size necessary for further development (Hairston et al. 1960, Hanski 1977).

The procedure employed in this study, albeit indirect and utilizing theoretical estimate of ECI, has some advantages over those that rely on physiological or behavioural parameters, in that (1) it makes use of quantities that have a direct bearing on ecological processes such as pupal size and competition, density dependence, and fitness traits such as survival; (2) these data can be easily obtained experimentally and directly employed in measures 
of population dynamics; (3) larval density is incorporated as an important variable in the calculations and (4) the method allows for a model evaluation of the theoretical estimates through comparisons with experimental data. In addition, in insects whose immature stages develop inside the food source, the measurement on the amount of food remaining after the larvae have pupated is problematic, because it is difficult to separate faeces from the remaining substrate. So, we believe the procedure outlined here may be applicable to other kinds of insects whose immature stages develop inside the food source, where the estimates of consumable food are difficult to obtain by traditional procedures.

\section{ACKNOWLEDGMENTS}

To the anonymous reviewer for making suggestions that improved the clarity of the manuscript.

\section{REFERENCES}

Barbehenn RV 1993. Silicon: an indigestible marker for measuring food consumption and utilization by insects. Entomol Exp App 67: 247-251.

d'Almeida JM 1989. Substratos utilizados para a criação de dípteros caliptratos no Jardim Zoológico do Rio de Janeiro (Rio-Zoo). Mem Inst Oswaldo Cruz 84: 257-264.

d'Almeida, JM 1993. Capture of caliptrate flies with different breeding substrates on beaches in Rio de Janeiro, RJ, Brazil. Mem Inst Oswaldo Cruz 88: 215264.

d'Almeida JM, Lopes HS 1983. Sinantropia de dípteros caliptratos (Calliphoridade) no estado do Rio de Janeiro. Arq Univ Fed Rur Rio de J 6: 39-48.

de Jong G 1976. A model of competition for food. I. Frequency dependent viabilities. Am Natur 100: 1013-1027.

Denno RF, Cothran WR 1976. Competitive interactions and ecological strategies of sarcophagid and calliphorid flies inhabiting rabbit carrion. Ann Entomol Soc Am 69: 109-113.

Farrar RR, Barbour JD, Kennedy GG 1989. Quantifying food consumption and growth in insects. Ann Entomol Soc Am 82: 593-598.

Godoy WAC, Reis SF, Von Zuben CJ, Ribeiro OB 1993. Population dynamics of Chrysomya putoria (Dipt., Calliphoridae). J Appl Entomol 116: 163-169.

Goodbrod JR, Goff ML 1990. Effects of larval population density on rates of development and interactions between two species of Chrysomya (Diptera: Calliphoridae) in laboratory culture. J Med Entomol 27: 338-343.

Greenberg B 1971. Flies and disease. Vol.1. Princeton Univ. Press, Princeton, 856 pp.

Guimarães JH 1984. Considerações gerais sobre moscas do gênero Chrysomya no Brasil. Agroquimica (CibaGeigy) 24: 8-12.

Guimarães JH, Prado AP, Linhares AX 1978. Three newly introduced blowfly species in Southern Brazil (Diptera: Calliphoridae). Revta bras Ent 22: 53-60.
Hairston NG, Smith FE, Slobodkin LB 1960. Community structure, population control, and competition. Am Natur 94: 421-425.

Hanski I 1976. Assimilation by Lucilia illustris (Diptera) larvae in constant and changing temperatures. Oikos 27: 288-299.

Hanski I 1977. An interpolation model of assimilation by larvae of the blowfly Lucilia illustris (Calliphoridae) in changing temperatures. Oikos 28: 187-195.

Hanski I 1987. Nutritional ecology of dung- and carrion-feeding insects, p. 837-884. In F Slansky and FG Rodriguez (eds), Nutritional ecology of insects, mites, spiders and related invertebrates. New York, John Wiley.

Hassell MP, Lawton JH, May RM 1976. Patterns of dynamical behaviour in single species populations. $J$ Anim Ecol 45: 471-486.

Heal OW 1974. Comparative productivity in ecosystems - secondary productivity. Proc 1st int Congr Ecology: 37.

Holter P 1973. A chromic oxide method for measuring consumption in dung eating Aphodius rufipes larvae. Oikos 24: 117-122.

Holter P 1982. Resource utilization and local coexistence in a guild of scarabaeid dung beetles (Aphodius spp.). Oikos 39: 213-227.

Kneidel KA 1984. Competition and disturbance in communities of carrion-breeding Diptera. J Anim Ecol 53: 849-865.

Leal TTS, Prado AP, Antunes AJ 1982. Rearing the larvae of the blowfly Chrysomya chloropyga (Wiedemann) (Diptera, Calliphoridae) on oligidic diets. Revta Bras Zool 1: 41-44.

Levot GW, Brown KR, Shipp E 1979. Larval growth of some calliphorid and sarcophagid Diptera. Bull ent Res 69: 469-475.

Linhares AX 1981. Synathropy of Calliphoridae and Sarcophagidae (Diptera) in the city of Campinas, São Paulo, Brazil. Revta bras Ent 25: 189-215.

Lomnicki A 1988. Population ecology of individuals. Princeton University Press, Princeton, New Jersey, $223 \mathrm{pp}$.

MATLAB 1987. PC-MATLAB for MS-DOS Personal Computers. The MathWorks, Inc.

McGinnis AJ, Kasting R 1964. Colorimetric analysis of chromic oxide used to study food utilization by phytophagous insects. J Agric Food Chem 12: 259-262.

Morris WF 1990. Problems in detecting chaotic behavior in natural populations by fitting simple discrete models. Ecology 71: 1849-1862.

Mueller LD 1988. Density-dependent population growth and natural selection in food-limited environments: the Drosophila model. Am Natur 132: 786-809.

Nicholson AJ 1954. An outline of the dynamics of animal populations. Aust J Zool 2: 9-65.

Norris KR 1965. The bionomics of blowflies. Ann Rev Entomol 10: 47-68.

Putman RJ 1977. Dynamics of the blowfly, Calliphora erythrocephala, within carrion. J Anim Ecol 46: 853866.

Reis SF, Stangenhaus G, Godoy WAC, Von Zuben CJ, 
Ribeiro OB 1994. Variação em caracteres bionômicos em função de densidade larval em Chrysomya megacephala e Chrysomya putoria (Diptera, Calliphoridae). Revta bras Ent 38: 33-46.

Rodriguez DJ 1988. Models of population growth with density regulation in more than one life stage. Theor Pop Biol 34: 93-117.

SAS Institute Inc. 1988. SAS/STAT User's Guide, Release 6.03 Edition. Cary, NC.

Schumann V 1971. Merkblätter über angewandte Parasitenkunde und Schädlingsbekämpfung. Angew Paras, Jg 12: H4.

Scriber JM, Slansky F 1981. The nutritional ecology of immature arthropods. Ann Rev Entomol 26: 183-211.

Slansky F, Scriber JM 1982. Selected bibliography and summary of quantitative food utilization by immature insects. Bull Ent Soc Am 28: 43-55.

Slansky F, Rodriguez JG 1987. Nutritional ecology of insects, mites, spiders and related invertebrates: an overview, p. 1-69. In F Slansky and FG Rodriguez (eds), Nutritional ecology of insects, mites, spiders and related invertebrates. New York, New York.

Travis J 1990. The interplay of population dynamics and the evolutionary process. Phil Trans Roy Soc Lond B330: 253-259.

Ullyett GC 1950. Competition for food and allied phenomena in sheep-blowfly populations. Phil Trans Roy Soc Lond B334: 77-174.

Varley GC, Gradwell GV 1960. Key factors in population studies. J Anim Ecol 29: 339-401.

Waldbauer GP 1968. The consumption and utilization of food by insects. Adv Ins Phys 5: 229-288.

Zheng Y, Hagen KS, Daane KM, Mittler TE 1993. Influence of larval dietary supply on the food consumption, food consumption, food utilization efficiency, growth and development of the lacewing Chrysoperla carnea. Entomol Exp App 67: 1-7.

Zumpt F 1965. Myiasis in man and animals in the Old World. Butterworths, London, 267pp. 